\title{
Effects of different ingredients on texture of ice cream
}

\begin{abstract}
Ice cream is a popular dairy product among consumers of all ages. Textural attributes of ice are the key factors determining the market success of the product. Ice cream is a dairy aerated dessert that is frozen prior to consumption. It is a microcrystalline network of liquid and solid phases. It contains air cells entrapped in liquid phase and various other components like proteins, fat globules, stabilizers, sugar, soluble and insoluble salts are also present in this phase. It is a complex physicochemical and colloidal system consisting on many complex ingredients that affect ice cream structure both in positive and defective functionality. Both stabilizers and emulsifiers improve the texture of ice cream by enhancing its viscosity and limiting the movement of free water molecules but their excess may cause the lower melting and less whip ability. As sugar provides sweet taste, improves thickness as well as bulkiness but on other hand its excessive use can turn ice cream into soggy structure above solid contents of about $42 \%$. One of its compositional contents, fat, also exerts good effects on body, texture, palatability, flavor intensity, emulsion formation and maintenance of melting point. If fat contents exceed a specific usage concentration they cause faster meltdown of ice cream along with destabilization and agglomeration of fat droplets. Higher overrun results in collapsing of air cells ultimately shrinkage of structure occurs. Hardness might also reduced as a result of smaller ice crystals due to high overrun values. Fiber addition causes the binding of free water hence flow rate get reduced and consistency coefficient as well as viscosity enhanced. Binding of water results in less availability of its molecules; freezing point rises and melting point decreases. It is much critical to control the balance ice cream properties by maintaining its structure, texture and body. It is a best carrier for fruit fiber, chunks, purees, paste, concentrates; milk and whey isolates and concentrates; egg, egg yolks and their products; different flavorings, nuts, chocolate, probiotics and yogurt. So far, it is important to maintain its solid contents and structure with balanced proportion of ingredients.
\end{abstract}

\author{
Volume 8 Issue 6 - 2018
}

\section{Qamar Abbas Syed, Saba Anwar, Rizwan} Shukat, Tahir Zahoor

National Institute of Food Science and Technology, University of Agriculture, Pakistan

Correspondence: Qamar Abbas Syed, National Institute of Food Science and Technology, Faculty of Food, Nutrition and Home Sciences, University of Agriculture, Faisalabad, Pakistan, Email Qamar.Abdas@uaf.edu.pk

Received: October 02, 2018 | Published: November 20, 2018

\section{Introduction}

Dairy product prepared by pasteurization, homogenization, aeration and freezing that has been maintained at uniform consistency is called ice cream. It is cheap, healthy, nutritious and palatable product. Composition of ice cream is comprised of sugar, fat, emulsifiers, stabilizers, water, egg and eggs products, corn syrup, dextrose and flavors. It is a three phase network consisting on air, solid and liquid in final product. Liquid phase contains ice crystals in embedded form and air cells in dispersed form. Milk proteins, soluble and insoluble salts, fat particles, stabilizers and sugars are also present in liquid phase. So it is a very complex physiochemical food system. Ice cream is categorized in dairy frozen desserts in which frozen confections, water ice, sherbet, frozen custard, parevine like products, ice milk and mellorine are included. According to U.S standards, ice cream must be consisted of not $<20 \%$ MSNF and $10 \%$ fat from milk while when flavors added in bulk than there should be $16 \%$ MSNF and $8 \%$ fat. Stabilizers should not be $>0.5 \%$.

\section{Composition}

Average ice cream composition is;

\begin{tabular}{lll}
\hline Ingredients & Quantity (\%) & Normal variation (\%) \\
\hline Sugar & 15 & $13-20$ \\
Fat & 12 & Aug-20 \\
MSNF & 11 & Aug-15 \\
Emulsifier and stabilizer & 0.3 & $0-0.7$ \\
Total solids & 38.3 & $36-43$ \\
\hline
\end{tabular}

On the basis of calorimetric measurements, $9.45 \mathrm{cal} / \mathrm{g}$ contributed from fat; $5.65 \mathrm{cal} / \mathrm{g}$ from proteins and $4.10 \mathrm{cal} / \mathrm{g}$ from carbohydrates.
All material is not absorbed in the body hence actually energy derived from fat, protein and carbohydrates is 9,4 and 4 respectively. ${ }^{1}$ 
Optional and essential compositional ingredients of ice cream

\begin{tabular}{|c|c|}
\hline Dairy ingredients & Sweetening agents \\
\hline Milk & Sugar \\
\hline Butter & Dextrose \\
\hline Butter oil & Honey \\
\hline Cream & Corn syrup \\
\hline Plastic cream & Invert sugar \\
\hline Anhydrous milk fat & Maple syrup and sugar \\
\hline Concentrated milk & Brown sugar \\
\hline Sweetened condensed milk & Lactose \\
\hline Evaporated milk & Refined syrup \\
\hline Dried milk & Fructose \\
\hline Dried cream & Malt syrup \\
\hline Sweet cream buttermilk & Sucralose, aspartame, acesulfame $k$ \\
\hline Skim milk & Caseinates \\
\hline Whey and modified whey products & Ammonium, $\mathrm{K}, \mathrm{Na}, \mathrm{Ca}$ caseinates \\
\hline Hydrolyzed milk proteins & Minerals \\
\hline Egg products & Citric acid as sodium salts \\
\hline Whole egg as liquid, frozen or dried form & Disodium phosphate \\
\hline Egg yolk as liquid, frozen or dried & Tetrasodium \\
\hline Emulsifiers & Calcium and magnesium oxide \\
\hline Polyoxyethlen sorbitan & Calcium hydroxide \\
\hline Mono and di glycerides & Stabilizers \\
\hline Monostearate 60 & $\begin{array}{l}\text { Gum guar, carrageenan, locust gum, alginate, gum acacia, } \\
\text { carboxymethyl cellulose, xanthan and karaya }\end{array}$ \\
\hline \multicolumn{2}{|l|}{ Monoloeate 80} \\
\hline \multicolumn{2}{|l|}{ Dioctyl sodium sulfosuccinate } \\
\hline Water: either evaporated from or mixed & \\
\hline
\end{tabular}

Marshall et al. ${ }^{2}$

\section{Ice cream and related dairy desserts}

Frozen custard/ French ice cream: 1.4\% solids from egg yolk

Reduced fat ice cream: $25 \%$ less fat than regular ice cream

Low fat ice cream: $<3 \mathrm{~g}$ fat/ serving of ice cream

Nonfat/ fat free/ no fat ice cream: $<0.5 \mathrm{~g}$ fat/ serving of ice cream

Sherbet: 1-2\% milk fat, $2-5 \%$ milk solids-not-fat contents, acidity minimum of $0.35 \%$

Water ices and Sorbet: no egg and milk contents

Frozen yogurt: $10 \%$ cultured yogurt ingredients, $0.3 \%$ mix titratable acidity

Gelato: served semi frozen state like soft ice cream with less overrun
Mellorine: fat from animal or vegetable sources are used, no milk fat added, not $<6 \%$ fat, minimum protein $2.7 \%$

\section{Commercial production of different ice creams}

\begin{tabular}{ll}
\hline Dairy product & Production (\%) \\
\hline Ice cream & 60 \\
Reduced fat & 28 \\
Frozen yogurt & 4 \\
Water ice and juices & 4 \\
Sherbet & 3.5 \\
Other frozen products & 0.5 \\
\hline
\end{tabular}

Kilara et al.3 
Many industries manufacture ice cream at global level such as General mills, Unilever and Nestle. In 2010, total production of ice cream was 16.3 billion liters in whole world and Pacific Asia was the top producing that was $31 \%$ of total production Marshall et al. ${ }^{2}$

\section{Compositional properties of ice cream}

Various ingredients are available in market for ice cream that have important effects on ice cream quality. These ingredients can be categorized in dairy and nondairy components from many sources. Various ingredients that affect the quality of ice cream include sugar, fat, MSNF, water, emulsifiers and stabilizers.

\section{Sugar}

Sugar either in liquid or solid dry form added in ice cream up to $12-20 \%$ but $14-16 \%$ is the preferable level. Corn syrup can be added to replace $45 \%$ sugar in ice cream to handle, store and economic purposes. Among various commercially available sugar blends, solids of corn syrups-low conversion preferred because they don't affect the characteristics of ice cream and enhance the total solids. Sucrose performs various functions in ice cream including;

\section{Functions}
i. Optimum palatability
ii. Maintain handling properties
iii. Acceptability of ice cream
iv. Sweetens the product
v. Increase pleasing sweet flavor
vi. Enhance solid contents and viscosity
vii. Texture and body improvement

\section{Defects}

Higher sugar addition causes bad effects like;
i. Bland taste due to lacking sweetness
ii. Mask desired flavor
iii. Soggy ice cream above $42 \%$ TS
iv. Freezing point depression
v. Freezing slow down
vi. Hardening require low temperature

\section{Total solids}

Total solids includes the sum of all solid and dry ingredients of ice cream. Fat, sugar, MSNF, stabilizers and emulsifiers all contribute to total solids. Water is replaced by total solids in ice cream mix. Properties of ice cream are specially improved by the addition of solids of buttermilk and egg yolk, sweet cream and eggs.

\section{Functions}
i. Texture and body improvement
ii. Whip ability improvement
iii. Freezing point reduction
iv. Increase overrun with increased TS

\section{Defects}

i. Decreased cooling effect during summer associated with increased TS

ii. Soggy and heavy structure with TS up to $40-42 \%$

\section{Water}

Mostly ignored but very influential component present in ice cream air and water. Water maintains the continuous phase in ice cream either by adding as solid or liquid form. Products from dairy origin also contribute water contents. Water provided from supply source must be purified while it is expected that water of milk source has been cleaned already during its passage and excretion from memory glands.

\section{Functions}

i. Act as solvent

ii. Provides liquid medium

Arbuckle. ${ }^{1}$

\section{Air}

During ice cream preparation, overrun is created by incorporating air in mixture to enhance the volume. Quality of ice cream is influenced by amount of air incorporated. Quality of product can be controlled by uniform addition of air. Air quality itself is maintained by filters installed in freezers. Emulsifiers, fat and protein in unfrozen state cause the stabilization of air and water interface by forming thin film. Fat globules, ice crystals and water form the emulsion and entrap the air.

\section{Functions}
i. Increase the volume
ii. Meeting legal standards
iii. Increase profit
iv. Product and quality control
v. Affect quality

\section{DefectS}

Air incorporation above certain level causes defects in ice cream;

i. Reduced ice crystals size

ii. Reduction in melting point

iii. Low hardness

For the injection of nitrogen instead of air, various researches has been performed. It was reported that rate of oxidation was reduced with incorporation of nitrogen., ${ }^{2,4}$

\section{Stabilizers}

Basic types of stabilizers added in ice cream are of two sources;

i. Animal source: gelatin from bones and calf skin

ii. Plant or vegetable source: gums (agar-agar, carboxymethyl cellulose, sodium alginate, acacia, oat, carrageenan and karaya) 
Water binding capacity of stabilizers is very high and added in small quantity hence effect on flavor and product value is inconsequential. Total solids, processing machine, stabilizers properties and some other factors affect the usage of stabilizers.

\section{Functions}
i. Smoothens the texture
ii. Provide body to the product
iii. Enhance viscosity
iv. Freezing point not affected
v. Prevent from texture coarsening
vi. Provide resistance during melting

\section{Defects}
i. Restrict whip ability
ii. Heavy and soggy structure
iii. Undesirable melting properties

\section{Emulsifiers}

During manufacturing of ice cream, emulsifiers are added to smoothen the texture and thorough distribution of air cells. Mono and di-glycerides are most common emulsifiers used in ice cream plants. Emulsifiers are not be used more than $0.2 \%$ on weight basis. Polysorbate and sorbitan tristearate up to $0.1 \%$ are now allowed in dairy products as safe.

\section{Functions}
i. Stiffness to body and smoothness of texture
ii. Reduction in time of whipping
iii. Even whip ability properties
iv. Smaller uniformly distributed air cells

\section{Defects}

Emulsifiers when used in excessive quantity cause defects like;
i. Slower melting
ii. Textural and body defects

\section{Egg yolk}

It is highly valuable in foods and helps in other flavors blending for desirable properties. Ice cream cost is increased by egg yolk addition. It provides desirable flavor to ice cream but if product of egg has any off flavor that can be easily detectable in ice cream with egg. Protein and lecithin complex in egg yolks is highly preferred in mixes where total solids are lowered and prepared with butter oil or butter.

\section{Functions}
i. Delicate characteristic flavor
ii. Texture and body improvement
iii. Viscosity increase
iv. Improved whip ability

\section{Defects}

i. Off flavor in egg yolk detectable in final product

\section{Flavors}

Flavor can be easily mistaken as taste or feel sensation. It is very important ice cream property and resulted from mixed flavor of all ice cream components. Individual taste of any ingredients has effect on "flavor blend" or "specific flavor" so it makes difficult in detection of specific ingredient effect on ice cream flavor. Important properties of flavor are intensity and type. They may be mild or harsh. Harsh flavors at even low concentration soon turn monotonous but mild flavor can be blended easily and at higher intensity they don't turn into monotonous. So delicate and mild flavors are generally preferred. Flavor must be detected easily and provides refreshing taste in all conditions.

\section{Properties of balanced ice cream mix}

A mix is named balanced if it has all ingredients or components proportion in a way that results in fine and desirable ice cream. If defects are present, they may not be eliminated by changing proportion of constituents and not resulted from poor mix balancing. Such defects are;

i. Flavor rancidity

ii. Lacking of uniformity in color

iii. Base flavor

iv. Some defects that resulted from poor balancing but can be corrected by alteration in mix proportion are;

v. Insufficient fat concentration and richness lacking

vi. Insufficient flavors percentage

vii. Sandiness due to high MSNF

viii. Weak body due to less stabilizers and TS

(Arbuckle, 2013). ${ }^{1}$

\section{Compositional factors affecting structure of ice cream}

\section{Fat effects}

Three different levels of whipping cream (3\%, $6 \%$ and $12 \%)$ were used in ice cream samples to evaluate the effect on physicochemical and flavor perception. Flavors were coconut, banana, berry and vanilla. Methodology used to analyze the samples was time-intensity method. All the fat levels showed an increase in melting rate due to increase of fat contents. Melting rate was higher in low fat ice cream. At $6 \%$ and $12 \%$ fat contents, no significant difference was observed among various flavors in $T_{\max }$ while shorter duration for vanilla and banana flavor found in ice cream of 3\% fat level. Flavor intensity increase was faster at initial stage at 3\% fat level in contrast to $6 \%$ and $12 \%$ fat that had reduced flavor intensity decrease (Frost et al., 2005). ${ }^{5}$ This study was aimed to investigate the interaction between emulsifier and different types of fat. Mono and di-glycerides (MDG) from vegetable fat were used in ice cream samples differing in saturation and unsaturation level. Unsaturated (MDG), saturated (SMDG) and partially unsaturated glycerides (PUMDG) were used in ice cream preparation. Both the emulsifier and fat influence the size of fat particles in ice cream. More destabilization of fat globules was 
observed due to unsaturated MDG while fat particles of reduced size in saturated MDG was seen in contrast to enhanced diameter when added partially unsaturated MDG. Melting rate was reduced with addition of PUMDG that might be explained by the resistance of ice cream towards melting due to aggregation of fat. From this study, it was concluded that fat globule size was hardly affected due to nature of fat. Moreover, not only size of fat globule but fat crystallization also contributed to the melting rate Granger et al. ${ }^{6}$

Ice cream with vanilla flavor were manufactured using high melting milk fat and anhydrous milk fat as substitutes of cream. Some samples contained emulsifiers while some samples were not emulsified. Physical and chemical analysis were performed to check the effects of emulsifier on quality. Acidity, $\mathrm{pH}$, fat and total solids were found same in both type of samples either emulsified or nonemulsified. Ice cream that contained cream had more viscosity as compared to anhydrous milk fat containing sample might be due to emulsification with phospholipids. Contrarily, low milk fat ice cream had the lower viscosity that could be explained by different composition of fatty acids in both fat types. Emulsifiers added mixes had more viscosity due to stickiness of fat particles. Viscosity increase was attributed to the solidification of fat due to aggregation during process of aging. More the unsaturated and short chain fatty acids in low milk fat fraction, lower were the rate of solidification hence less solidified fat. Cream added mix with no emulsifier had resulted in significantly enhanced solidified fat contents. Solidification effect could be explained by the emulsification due to phospholipids present in cream (Figure $1 \& 2$ ).

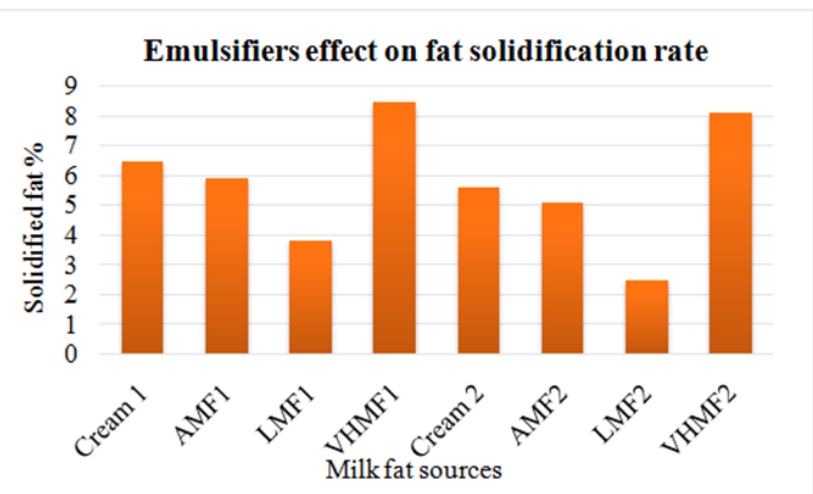

Figure I Changes in solidified fat \% due to fat source differences after 24 hour of storage.

Fat sources with emulsifiers: Cream I, AMFI, LMFI and VHMFI; Fat sources without emulsifiers: Cream2, AMF2, LMF2 and VHMF2. On the other hand, increased solidified fat and solidification rate was observed due to emulsifier addition.

Ice cream hardness was not affected by the addition of low milk fat, anhydrous milk fat, very high melting milk fat and cream but emulsifiers had influence on hardness. Drier product with smoother texture and body was obtained with addition of emulsifier. Melting of $50 \%$ ice cream required the longer time for first dripping hence rate of melting was low for very high melting milk fat added ice cream. Proteins adhered at the surface of water and fat molecules due to emulsifier action that resulted in improving the meltdown property. Emulsifiers caused the agglomeration of fat which in turn finely dispersed and stabilized the air cells. ${ }^{7}$ It is believed that size of fat globules have significant effect on melting property of ice cream. So this effect was checked in the following study. Three types of homogenization processes (single stage, double stage and selective homogenization) were applied in ice cream samples containing $10 \%$ fat contents. In addition to meltdown test, free fat and size of fat globules were also determined in molten and mix ice cream samples. In melted serum phase, size of fat aggregates had affected the ice cream meltdown. Different conditions of pressure were used during homogenization of ice cream mix and $80 \%$ aeration level (overrun) was adjusted. Increase in homogenization pressure caused the reduction in size of fat globules and vice versa. Shear forces during freezing resulted in fat particles damage which in turn caused the aggregation and fluid fat release. Less pressure during homogenization resulted in increased size of fat particles which were more vulnerable towards shear forces. Significantly high amount of fat was observed in ice cream in aged and homogenized ice cream while only $<0.1 \%$ fat was found in extracted form. Inhomogeneous pattern and faster melting was observed in ice cream at 30/6 homogenization level. It was clear from the curve that melting of ice cream occurred rapidly below specific size of globules $(\sim 0.85 \mu \mathrm{m})$ (Figure 3 ).

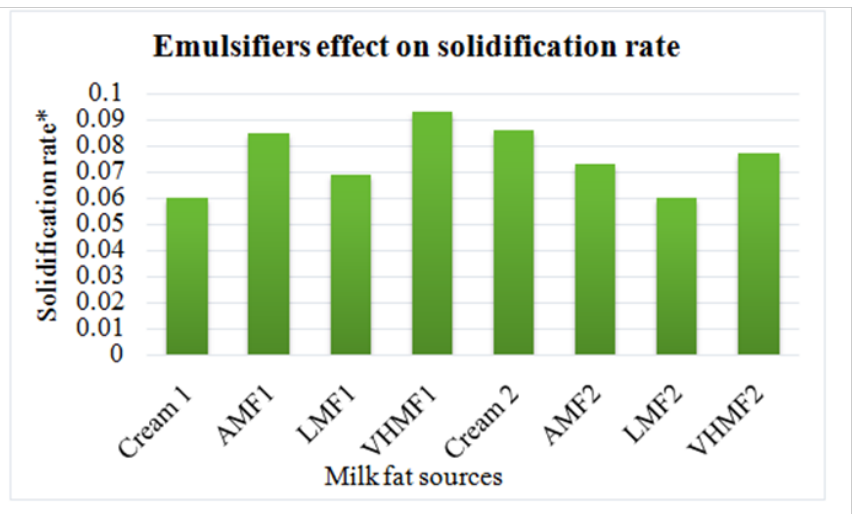

Figure 2 Changes in solidification rate of fat in ice cream prepared with different fat sources.

*Solidification rate was calculated using equation of regression.

\section{Fat globules size after homogenization}

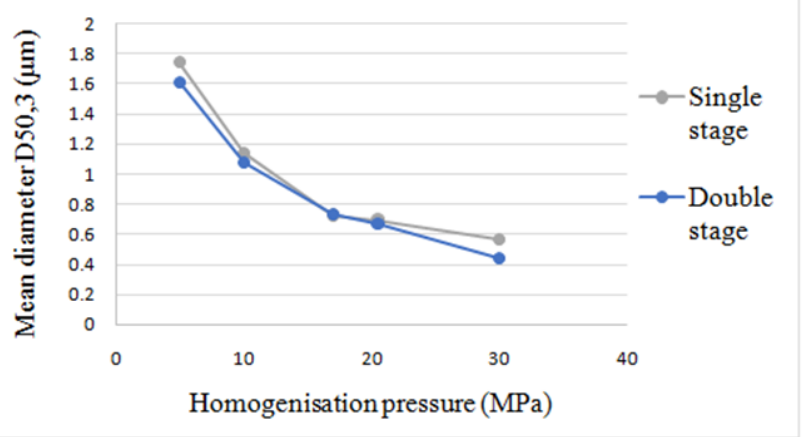

Figure 3 Homogenization effect on mean diameter $\left(D_{50,3}\right)$ of fat globules.

With the increase of further globules above this critical size, melting had occurred very slowly. Melting rate was maximum affected by the drip losses containing fat which in turn affected by the size of fat particles. Melted ice cream had contained fat of smaller size than critical fat globules size while foam contained maximum fat of bigger globules as compared to critical fat diameter. From the results, it was concluded that fat globules size had major effect on ice cream melting rates but the foam structure had not been stabilized because the free fat was not enough to form continuous network. 
Attachment of fat agglutinates at the surface of protein membranes present on fat globules prevented the destabilization of air cells in homogenized ice cream. Moreover, it was also concluded from the study that it might be possible to prepare ice cream using partial or selective homogenization without any damage to ice cream structure. In this study, fat was replaced either with simplesse or Dairy Lo and 3 batches ( 4 treatments) of ice cream was prepared with cocoa butter $(2.5 \%)$ and milk fat $(2.5 \%)$. Ice cream was analyzed for physical changes in melting, hardness and viscosity. Hardness was measured with penetrating probe; viscosity measured through shear forces exerted by viscometer spindle while wire mesh of $2.33 / \mathrm{cm}^{2}$ size used to determine melting rate of ice cream samples (Table 1).

Table I Effect of fat and fat replacers on composition of ice cream at 0 wk.

\begin{tabular}{lll}
\hline Fat/ fat replacer & Fat (\%) & Total solids (\%) \\
\hline Milk Fat & 2.2 & 39.8 \\
Cocoa Butter & 2 & 40.2 \\
Simplesse & 0.7 & 39.6 \\
Dairy Lo & 0.7 & 40.9 \\
\hline
\end{tabular}

Hardness was not differed significantly in all treatments. Ice cream sample containing Dairy Lo (DL) was found more viscous as compared to other samples that showed similar viscosity. There was a significant difference of melting rates among all samples. Higher melting rate was observed in sample prepared with cocoa butter $(\mathrm{CB})$ while milk fat ice cream had the slowest meltdown. On melting, cocoa butter sample formed a thin liquid; foamier liquid shape maintained by simplesse; thick liquid by milk fat sample and color separated foamy liquid with poor drainage shown by Dairy Lo sample. Maximum emulsion and its stabilization was noticed in milk fat samples that maintained their structure longer as compared to other samples. From the study, it was summarized that icy structure was slowly developed by the simplesse as compared to DL. Hedonic evaluation resulted in same consumer acceptance for all samples of cocoa ice cream. Replacement of MF with $\mathrm{CB}$ resulted in less creaminess and mouth coating but it turned icy after storage. ${ }^{9}$ Sweetness, flavor and textural characteristics were evaluated in ice cream samples differing in sugar, fat and total solids. Composition of ice cream mixes was given below; Flavor parameters to be evaluated were milky, creamy, buttery, whey-like, caramel and phenolic while textural properties included meltdown, perception of ice crystal, firmness and coldness (Table 2).

Table $2 \%$ Formulation of ice cream

\begin{tabular}{|c|c|c|c|c|}
\hline Ingredients & $F \times N \times S I=(3 \times 8 \times 12)$ & $F \times N \times S 4=(3 \times 16 \times 20)$ & $F \times N \times S 5=(8 \times 12 \times 17)$ & $F \times N \times S 9=(12 \times 16 \times 20)$ \\
\hline Butter & 3.5 & 3.5 & 9.6 & 14.2 \\
\hline Skim milk & 64 & 67.1 & 67.7 & 54.9 \\
\hline Skim milk powder & - & 7.6 & 5.2 & 9.1 \\
\hline Sucrose & 9 & 15 & 12 & 15 \\
\hline Stabilizer & 0.5 & 0.5 & 0.5 & 0.5 \\
\hline Water & 19.2 & - & - & - \\
\hline
\end{tabular}

Less milk-solids not fat (MSNF) and higher fat contents caused rich mouth coating but textural attributes were reduced. Increase in fat contents restricted the growth of ice crystals mechanically and smaller crystals formation occurred which affected the rate of melting. Addition of fat had not significantly affected the sweetness but it caused the reduction in vapor pressure of flavoring chemicals. Fat addition increased the buttery and creamy flavor in contrast to no effect on milky, phenolic, whey-like and vanilla notes. Caramel flavor was only enhanced with increased MSNF and fat. Decrease in vanilla flavor was noticed when whey protein concentrates were added that could be attributed due to condensation of aldehyde and casein. As the MSNF contents were enhanced, the creamy, phenolic, buttery and caramel notes were also enhanced. On the other hand, ice crystals, coldness and meltdown were reduced with MSNF addition. There was an inverse relationship between size of ice crystals and total solids in a way that total solids might enhanced the viscosity which restricted the diameter of ice crystals. Fattiness was increased with enhancing sugar level but it reduced the milky flavor intensity and it proved to be modifier of flavor profile. ${ }^{10}$

This study presented the perception of vanillin flavor through sensory analysis and determination of free vanillin percentage using HPLC in ice cream samples differing in fat contents. There were prepared 7 samples $(1,2,3,4,5,6$ and 7$)$ with decreasing fat percentage such as $10 \%, 8 \%, 6 \%, 4 \%, 2 \%, 1 \%$ and $0 \%$ respectively. Physical analysis showed that enhanced fat caused enhanced viscosity. High amount of total solids also caused higher melting rate due to high fat contents. This could be explained as ingredients soluble in water were higher as compared to low fat samples and resulting freezing point depressed (Figure 4). Sensory evaluation showed that higher fat contents were needed by flavor molecules of lipophilic nature to interact inversely with food. So the time for maximum flavor intensity was less in low fat ice cream samples (Figure 5). Consumers preferred the samples with increased fat contents because of attribute that mouth was more coated with viscous ice cream and flavorants didn't diffuse rapidly but took time to reach maximum intensity. ${ }^{11}$

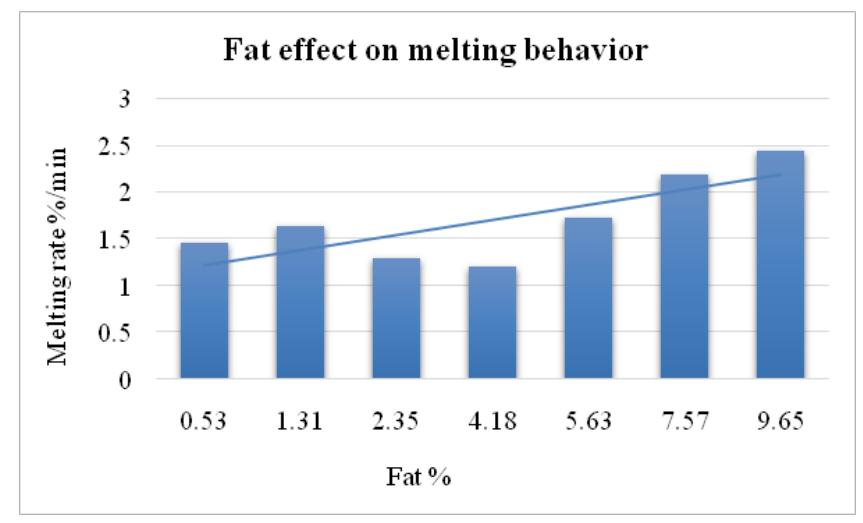

Figure 4 Meltdown changes with increasing fat percentage. 


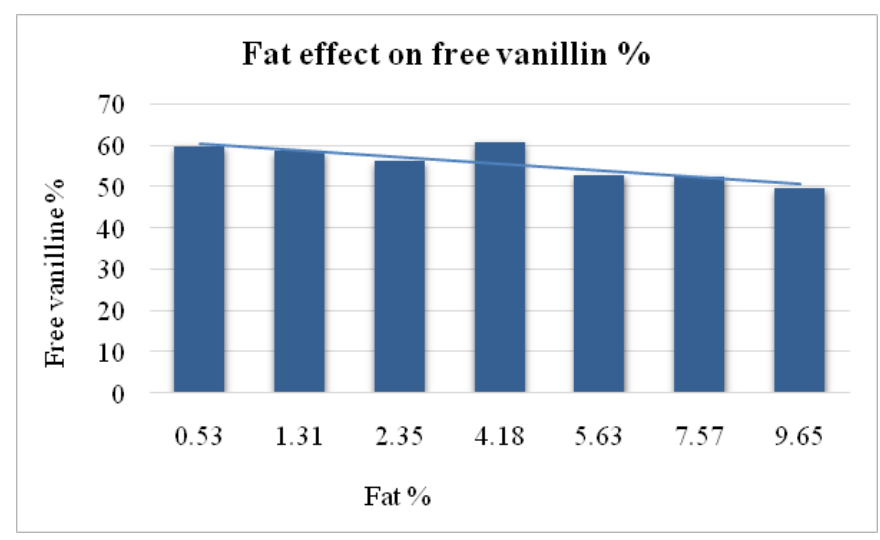

Figure 5 Percentage of free vanillin in ice cream with increasing fat \% measured by HPLC.

To check the temperature effects during storage, a study was carried out on full fat and low or light fat ice creams. 4 freezing temperatures applied during storage were $-28.9^{\circ} \mathrm{C}$ (control), $-23.3^{\circ} \mathrm{C}, 26.1^{\circ} \mathrm{C}$ and $45.6^{\circ} \mathrm{C}$. Ice crystals images were taken after storage for $1,19.5$ and 39 weeks. Fat contents were set at $5.20 \%$ in LF and $10.30 \%$ in HF ice cream. Size of ice crystals was higher in LF ice cream due to less total solids and high water percentage available for freezing. On the other hand, improved texture and body was observed in higher total solids containing ice cream. Low fat ice cream had the larger ice crystals as compared to full fat ice cream after 7 days of storage. Size of crystals had been increasing as the duration of storage prolonged. After 19.5 and 39 weeks storage, no temperature change was occurred. Moreover, heat shock effect was much greater on crystal size in low fat ice cream in a way size increased significantly. Full fat ice cream also exhibited increase in crystal size but relatively crystals remained smaller. Both temperature and mix affected the creaminess, iciness and cold intensity. Sensory analysis resulted in no significant effects on both full fat and low fat ice creams (Figure 6). It was concluded that either full fat or low fat ice cream storage at lower or higher temperature as compared to $28.9^{\circ} \mathrm{C}$ caused no effect on quality parameters. ${ }^{12}$

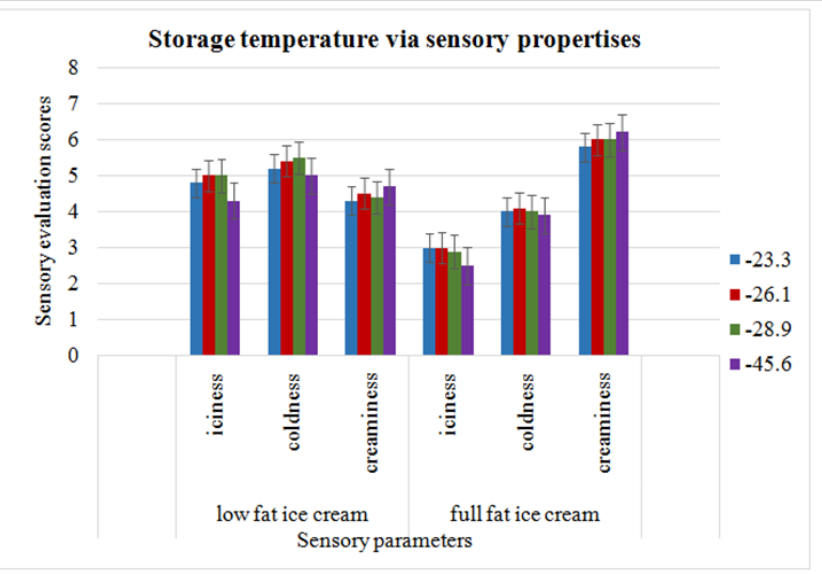

Figure 6 Sensory evaluation after storage at different temperatures of full fat and light fat ice cream.

\section{Fibre effects}

Four types of dietary fibres such as apple, oat, inulin and wheat were used in ice cream preparation to check their effect on ice cream texture. Ice creams samples were prepared using 2 different percentages for each type of fibre as $2 \%$ and $4 \%$ while the remaining ingredients added according to standard quantity. Increasing consistency and viscosity in turn reducing flow rates had indicated the significant effect of fibres on ice cream texture. It was assumed that both soluble and insoluble fibres contributed towards ice cream mix properties hence viscosity enhanced. With the addition of inulin, concentration of serum was enhanced, so the viscosity also, that resulted in more retention of water due to soluble contents of fibre. More water binding with insoluble portion of wheat and oat fibre also caused increased viscosity (Figure 7). On the other hand, depression of freezing point was occurred with increasing concentration of serum. Significant reduction in freezing point was noted when oat and wheat fibres added in contrast to inulin and apple fibres that caused higher freezing point. Reduction in freezing point with the addition of wheat and oat might be attributed to their ability for binding high water contents because of more concentration in serum hence water was more in frozen form. Higher water soluble contents of inulin and apple fibre caused the liquid phase enrichment so freezing point was decreased moderately and percentage of water in frozen form also reduced. Furthermore, temperature of melting was reduced significantly with increasing fibre contents. Melting of ice crystals required low temperature because of their dispersion in ice cream homogeneously. ${ }^{13}$

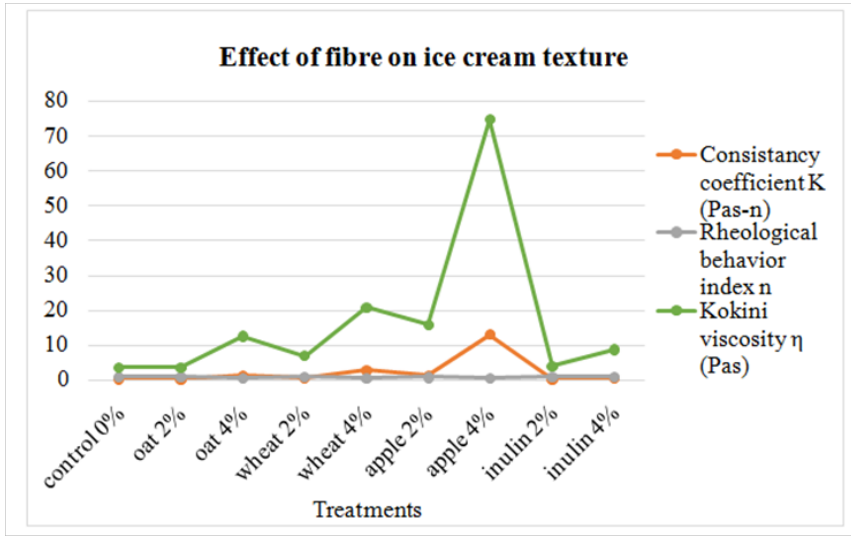

Figure 7 Rheological changes in ice cream samples with and without added dietary fibre.

Incorporation of persimmon puree was studied in ice cream using its different percentage contents as $8 \%, 16 \%, 24 \%, 32 \%$ and $40 \%$ for its effect on sensory, textural and physicochemical characteristics. Ice cream samples were prepared following standard method of manufacturing with addition of persimmon puree and sugar contents were determined through HPLC. Chemical analysis resulted in reduced total solids, protein, fat and ash contents. Ice cream with $24 \%$ added persimmon contents had $7.0 \mathrm{pH}$ that was enhanced while reduction in $\mathrm{pH}$ noticed with increased persimmon concentration $(40 \%)$ (Figure 8). Physical analysis showed significant viscosity reduction; color lightness reduced to 50.56 in $40 \%$ persimmon added ice cream as compared to control that had 70.11. Increasing percentage of persimmon enhanced the melting time. Ice cream with $40 \%$ puree took longer time than the control sample. Significant increase in fructose and glucose level was noticed in persimmon enriched ice cream; in contrast, reduction occurred in lactose concentration (Figure 9). Decrease in sucrose percentage was occurred due to medium dilution. Higher contents of $\mathrm{K}$ were recorded after mineral analysis because of the reason that persimmon contained high $\mathrm{K}$ level. Increase in persimmon concentration caused enhanced hardness in ice cream samples due to increasing stickiness. As desirable properties 
were observed in ice cream containing persimmon contents so it was concluded that this fruit might be used for enrichment purposes because it provided antioxidants like phenolic compounds. ${ }^{14}$

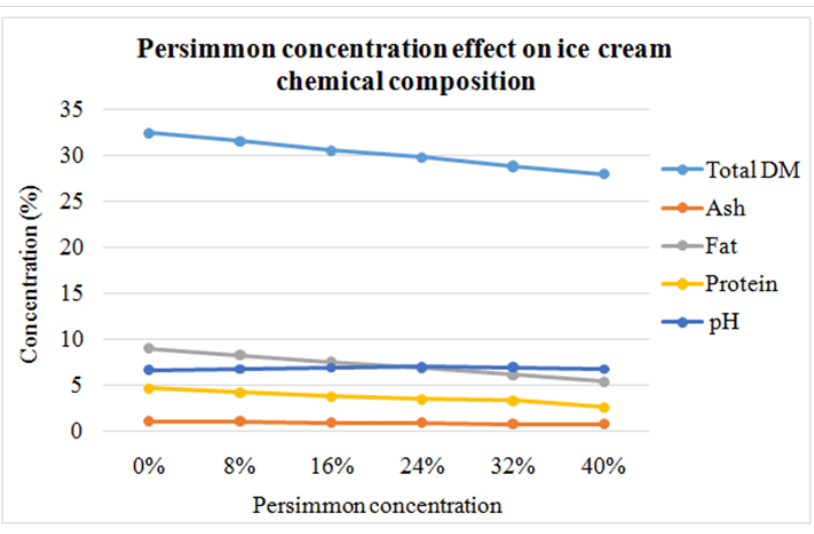

Figure 8 Chemical characteristics of ice cream with and without added persimmon puree.

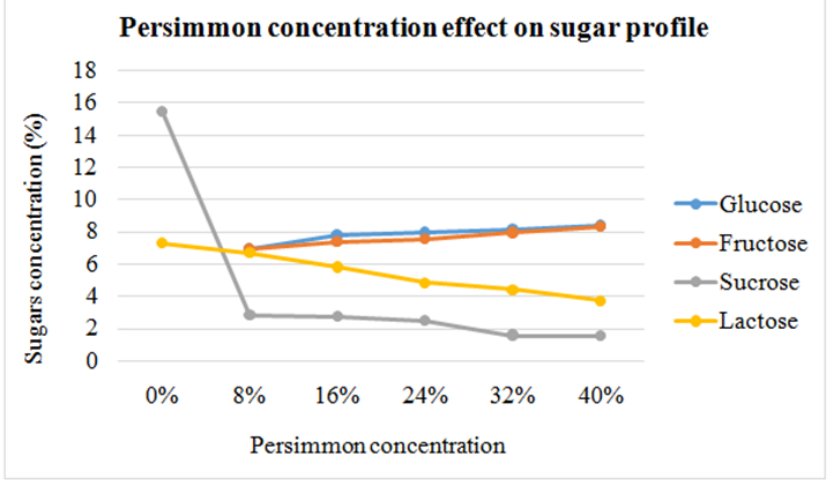

Figure 9 Effect of persimmon puree concentration on sugars profile of ice cream.

Rheological properties of ice cream, manufactured with inulin, sugar and cow milk, were investigated in the following research. Effect of temperature on viscosity of salep containing ice cream was checked. Salep was added as stabilizing agent and ice cream samples prepared adjusting their composition according to salep concentrations as 0.4 , $0.62,0.78$ and $1 \%$. Viscosity change in accordance with changing temperature was measured with a viscometer at $10-50^{\circ} \mathrm{C}$ with the difference of $10^{\circ} \mathrm{C}$. Salep enriched ice cream samples exhibited shear thinning property at all temperatures. Salep contents enhanced the viscosity while the increasing $\mathrm{rpm}$ of viscometer reduced it. Overall, milk-salep-sugar samples had more viscosity as compared to water-salep-sugar samples. ${ }^{15}$ Probiotic ice cream was prepared with fermented milk and level of sugar percentage kept different as $15 \%$, $18 \%$ and $21 \%$ in all samples. Inulin added fat free milk was used for culturing probiotic bacteria $(0.03 \%$ starter culture $)$ and incubated for 12 hours at $37^{\circ} \mathrm{C}$. Skim milk contained $1-2 \%$ inulin and $10 \%$ of that fermented milk was used in each sample of ice cream. Both the sugar and inulin affected sensory and physical characteristics of ice cream. Chemical analysis resulted reduction in $\mathrm{pH}$ of ice cream but acidity enhanced as a result of inulin addition. Change in acidity could be explained as inulin might have started the metabolism of probiotics hence acidity increased. Increase in sugar concentration up to $20 \%$ raised the overrun. Moreover, increasing sugar concentration enhanced the viscosity and first dripping and $15 \%$ sugar level showed highest time of melting completely. Inulin had not affected the overrun but it increased the viscosity, dripping and complete melting duration at $2 \%$ addition level. As inulin being hygroscopic, it might have interacted with water molecules and restricted their movement freely in mix. Such stabilizing action of inulin retarded the melting of product (Figure 10).

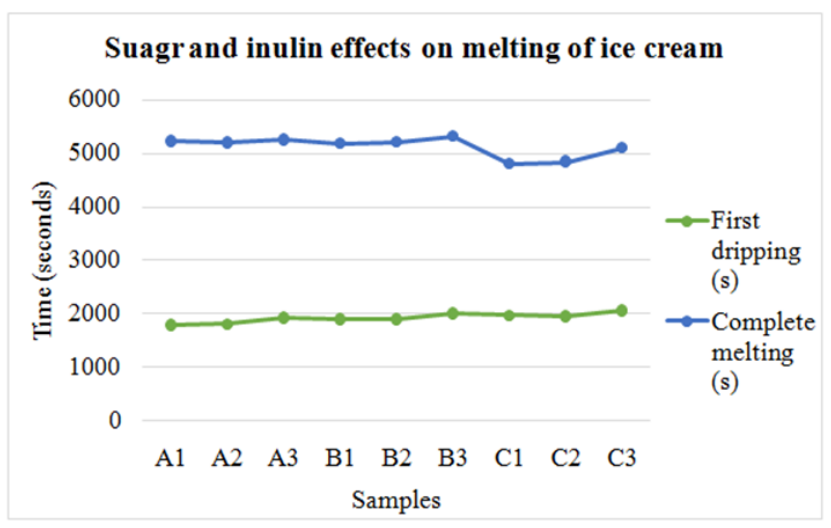

Figure 10 Changes in physical quality of ice cream due to insulin and sugar addition.

Furthermore, freezing caused the bacterial cells death due to damage of cells. Bacillus lactic and Lactobacillus thermophilus were enhanced because of inulin prebiotic action. Effect of inulin as prebiotic was best at $2 \%$ level. On the other hand, Lactobacillus delbrueckii ssp. bulgaricus and Streptococcus thermophilus were not affected by inulin addition. Sensory analysis resulted that increasing sugar concentration improved that flavor, creaminess, aroma and texture of the ice cream in contrast to inulin showed no change in sensory characteristics. Storage caused no bad flavor. It was concluded that inulin and sugar both improved the physical qualities while sugar alone increased the sensory quality and no effect was shown by inulin (Figure 11). ${ }^{16}$

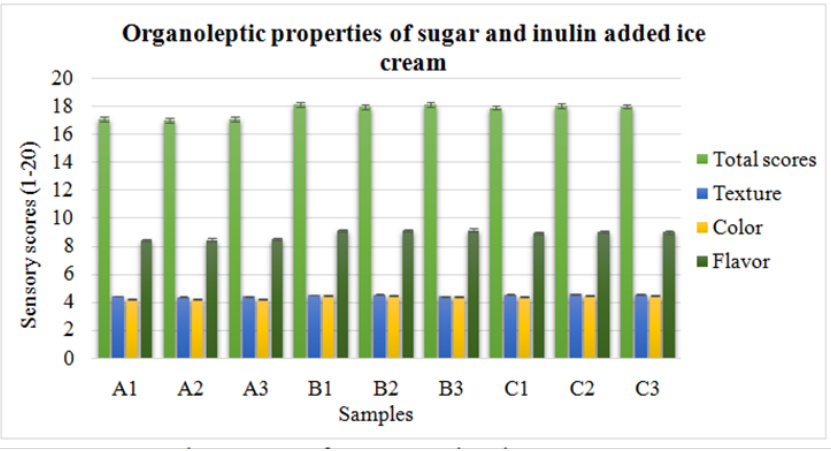

Figure II Sensory characteristics of ice cream with probiotics.

\section{Stabilizers effect}

Initially stabilizers were given the name as holders, binders, fillers, improvers, hydrocolloids, gums and colloids due to their specific functionality of influencing the body and texture of the product. The compounds were characterized with long chain polysaccharides that had the ability of binding water, fats and some proteins. It was reported that stabilizers can smoothen the texture and body of ice cream by reducing crystals and ice formation. Some of the stabilizers and their characteristics are given below (Table 3); it was reported that stabilizers influence the mixture viscosity. The texture smoothness 
and melting resistance of the ice cream are directly proportional to the viscosity increase while invers relation has been found with whipping rate. There exist incompatibility between commercially available stabilizers and proteins. They cause visible serum and liquid separation and the appealing appearance of product losses. Phase separation effects are different for different gum types as xanthan was found highly unsuitable for proteins. Phase separation can be controlled with addition of secondary stabilizer like carrageenan which forms a gel like structure by adsorbing on casein particles. As a result casein get precipitated by forming linkages with carrageenan. Ice cream containing stabilizers has smaller sized air cells due to

Table 3 Brief description of widely used stabilizers and their characteristics. enhanced forces of shear as a result of enhanced viscosity that causes the less entrapment of air in cells. Changes like drainage, coalescence, disproportionation and Ostwald ripening occur during storage. These mechanism were found dependent on the addition of stabilizers as well as temperature during storage. Stabilizers caused the viscosity increase hence coarsening of air cells was prevented. Various studies have been conducted on sensory quality of ice cream added with stabilizers. Studies have been resulted in improved body, mouth feel, texture and acceptability. It was concluded from the study that stabilizers had major effect on physical and sensory characteristics of ice cream. ${ }^{17}$

\begin{tabular}{|c|c|c|c|}
\hline Stabilizer and their EU No. & Source & $\begin{array}{l}\text { Usage } \\
\text { concentration }\end{array}$ & Functions \\
\hline Gelatin (E44I) & Animals protein derivative & $0.3-0.5 \%$ & $\begin{array}{l}\text { - Form thin mixes } \\
\text { - No wheying-off } \\
\text { - No foaming }\end{array}$ \\
\hline Guar gum (E4|2) & $\begin{array}{l}\text { Seeds of guar legume (Cyamoposis } \\
\text { tetragonolba) }\end{array}$ & $0.1-0.2 \%$ & $\begin{array}{l}\text { - Strong stabilizer } \\
\text { - Decrease heat shock effects } \\
\text { - No excess viscosity }\end{array}$ \\
\hline Sodium carboxymethyl cellulose (E466) & Chemically modified natural gum & $0.1-0.2 \%$ & $\begin{array}{l}\text { - Strong stabilizer } \\
\text { - Form weak gel } \\
\text { - Provides chewiness and body }\end{array}$ \\
\hline Locust bean gum (LBG) (E4I0) & Beans of (Ceratonia siliqua) & $0.1-0.2 \%$ & $\begin{array}{l}\text { - Strong stabilizer } \\
\text { - Cause phase separation } \\
\text { - Partially soluble in cold water } \\
\text { - Uniform viscosity } \\
\text { - Heat shock resistance } \\
\text { - Cryo-protective agent }\end{array}$ \\
\hline Carrageenan (E407) & Red seaweed (Condus crispus) & $0.01-0.02 \%$ & $\begin{array}{l}\text { - Used in stabilizers blends } \\
\text { - Prevention from phase separation }\end{array}$ \\
\hline Xanthan (E4I5) & $\begin{array}{l}\text { Bacterial exopolysaccharide (Xanthomonas } \\
\text { compestris) }\end{array}$ & & $\begin{array}{l}\text { - Blended with guar and LBG } \\
\text { - Used in sherbet, water ice and ice milk } \\
\text { - Act as milk shake stabilizer with Na-alginate }\end{array}$ \\
\hline Na-Alginates (E40I) & $\begin{array}{l}\text { Brown seaweed (Phaeophyceae) } \\
\text { Derivatives and salts of alginic acid, } \\
\text { insoluble acidic polysaccharide salt with } \\
\mathrm{Ca}, \mathrm{Na}, \mathrm{K} \text { and } \mathrm{Mg}\end{array}$ & & $\begin{array}{l}\text { - Dissolve in cold water } \\
\text { - Not commonly used } \\
\text { - Form gels in Ca and acids presence }\end{array}$ \\
\hline Microcrystalline cellulose (E460) & & 0.004 & $\begin{array}{l}\text { - Stabilize the foam } \\
\text { - Control the overrun } \\
\text { - Maintains texture during storage } \\
\text { - Enhance heat shock resistance } \\
\text { - Whey separation prevention } \\
\text { - } 2-4 \% \text { reduction in fat }\end{array}$ \\
\hline
\end{tabular}

Many stabilizers were used in ice cream preparation for the investigation of their effects on flow characteristics. Karaya, guar gum, ghatti gum, gelatin, acacia gum and sodium alginates were used at the concentration levels given below (Table 4); Results showed that when stabilizers added at optimum concentration level, the shear stress and shear rate were enhanced and the viscosity of mixes reduced dynamically. Samples showed the pseudoplastic behavior and $<1$ values of flow behavior index were found in all samples with stabilizers at optimum concentration. Consistency coefficient of all the stabilizers was found in following order; Sodium alginate $>$ gelatin $>$ karaya $>$ guar $>$ acacia $>$ ghatti $>$ control Sodium alginate had the highest consistency (1.19) as compared to others and it was lowered in control sample (0.290) (Figure 12).
Table 4 Concentrations of different stabilizers used in ice cream preparation

\begin{tabular}{lllll}
\hline Stabilizer & \multicolumn{4}{c}{ Concentration levels (\%) } \\
\hline Gelatin & 0.15 & 0.3 & 0.45 & 0.6 \\
Sodium alginate & 0.2 & 0.3 & 0.4 & 0.5 \\
Gum acacia & 0.25 & 0.5 & 0.75 & $\mathrm{I}$ \\
Gum guar & 0.025 & 0.05 & 0.075 & 0.1 \\
Gum ghatti & 0.25 & 0.5 & 0.75 & $\mathrm{I}$ \\
Gum karaya & 0.05 & 0.15 & 0.25 & 0.35
\end{tabular}




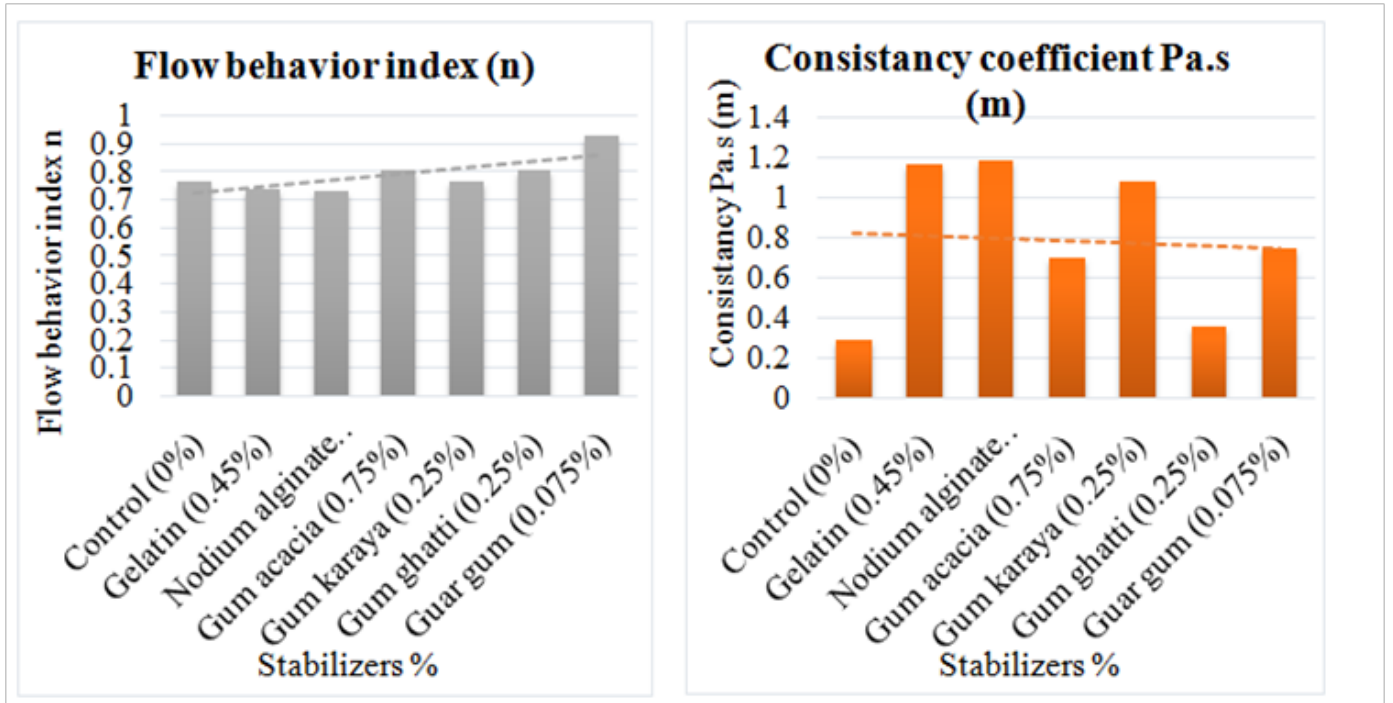

Figure 12 Flow behavior index $\mathrm{n}$ and the consistency coefficient of ice cream prepared with different stabilizers at optimum concentrations after aging of 4hours.

Mixes viscosity was highly related to the stabilizers percentages which in turn had effects on ice cream texture. Some stabilizers like sodium alginate and gum ghatti at certain concentration levels resulted in no or poor relation with ice cream texture. Sodium alginate, karaya, acacia, gelatin and guar gums also affected the acceptability of ice cream but ghatti had the lowest effect. Poor texture and body of ice cream was observed with sodium alginate and karaya gum. ${ }^{18}$ Xanthan gum, guar gum, carboxymethylcellulose and sodium alginate were added in ice cream mixes along with secondary stabilizer (carrageenan) to check their effects on physical, rheological and sensory properties. Stabilizers were used separately at two levels $(0.1 \%$ and $0.2 \%)$ as well as in combination with carrageenan at concentration levels of $0.01 \%$ and $0.02 \%$. formulation of stabilizers separately and with combination was given as (Table 5); Ice cream was prepared and analyzed for its sensory, physical and flowing attributes. Addition of xanthan and sodium alginate at $0.2 \%$ level resulted in highest viscosity due to more water retention. Increased pseudoplasticity was observed with the addition of $\kappa$-carregeenan might be due to gelation process. Xanthan gum behaved independently even in the presence of carrageenan. It was observed that ice cream mixes prepared with gum guar and $\mathrm{CMC}$ were more affected by addition of carrageenan as compared to xanthan gum and sodium alginate. As xanthan and sodium alginate could form the stabilized air cells with enlarged polymers so the overrun was found increased in all samples prepared with these two stabilizers.

Furthermore, stabilizers could hinder the free movement of water molecules to and from the ice crystals so they performed the action of cryoprotection. Recrystallization and collision of ice crystals was prevented due to water movement control when sodium alginate used in ice cream. During storage, non-gelling activity of sodium alginate and xanthan gum was observed due to mechanism of melt-diffuseregrow. Melting rate was decreased as a result of increased level of hydrocolloids. Time for the diffusion of water from interior to exterior was increased due to enhanced viscosity of ice cream containing stabilizers. From the current study, it was concluded that action of primary stabilizers was favored by secondary stabilizing agent which caused the gelation of casein micelles (Figure 13). Moreover, enhanced physical, sensorial and cryoprotective action was observed with addition of xanthan gum and sodium alginate. ${ }^{19}$
Table 5 Concentrations of primary and secondary stabilizers in current study

\begin{tabular}{lll}
\hline \multirow{2}{*}{ Mix samples } & \multicolumn{2}{l}{ Stabilizers concentration $(\%)$} \\
\cline { 2 - 3 } GI & Primary stabilizers & Secondary stabilizer \\
G2 & 0.1 & - \\
CI & 0.2 & - \\
C2 & 0.1 & - \\
XI & 0.2 & - \\
X2 & 0.1 & - \\
AI & 0.2 & - \\
A2 & 0.1 & - \\
GKI & 0.2 & - \\
GK2 & 0.09 & 0.01 \\
XKI & 0.18 & 0.02 \\
XK2 & 0.09 & 0.01 \\
AKI & 0.18 & 0.02 \\
AK2 & 0.09 & 0.01 \\
CK1 & 0.18 & 0.02 \\
CK2 & 0.09 & 0.01 \\
\hline
\end{tabular}

\section{Overrun effects}

Entrapment of air up to $80 \%, 100 \%$ and $120 \%$ level was ensured in ice cream samples and stored in containers at $-10^{\circ} \mathrm{C}$ and on microscopic slides at $-6^{\circ} \mathrm{C}$ to $-20^{\circ} \mathrm{C}$. Manufacturing of ice cream was done according to the standard procedure and air incorporated for desired overrun values. Increased overrun values caused collapsing of big sized air cells and small air cells created. As well as during freezing the viscosity was also increased with increased overrun resulting in efficient creation of smaller air bubbles. Hardening caused the air cells to increase in size in all samples. Relatively size of air 
cell was more in ice cream with $80 \%$ air incorporation as compared to $120 \%$ incorporation level. But all samples had the reduced cells and reduction was continued during storage at $-10^{\circ} \mathrm{C}$. Increase in overrun values also caused the reduction in mean sizes of the ice crystals. Almost the same size of ice crystals was observed in $80 \%$ and $100 \%$ air incorporated ice cream samples indicating that overrun had small effect on mean crystals sizes (Figure 14). Recrystallization rate was higher in ice cream with $80 \%$ overrun value showing relatively larger sized crystals. Rate of heat transfer was changed with increasing overrun as enhanced overrun resulted in slightly smaller sized ice crystals. Significant change in hardness was observed in samples with overrun of $80 \%$ and $100 \%$ as compared to $120 \%$ overrun samples that had reduced hardness. Hardness was similar in samples prepared with overrun values of $80 \%$ and $100 \%$. Measurement of melting rates was done after storage at $-30^{\circ} \mathrm{C}$ for 8 days showed highest melting in lowest overrun. Melted volume of ice cream samples was same for all overrun values and difference was not significant. Possibly the melting rate was lowered due to enhanced destabilization of fat with increasing viscosity as a result of increasing overrun. It was concluded from the study that more forces of shear due to enhancing overrun might cause the decreased ice crystals and air cells size. ${ }^{4}$

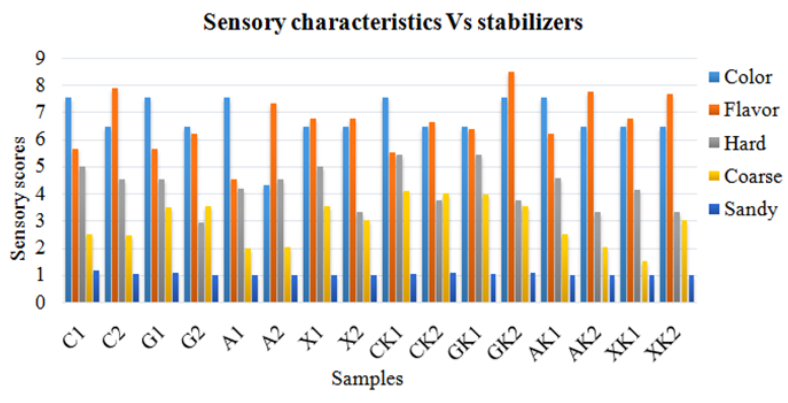

Figure 13 Sensory characteristics of samples containing primary and secondary stabilizers after storage of one month.

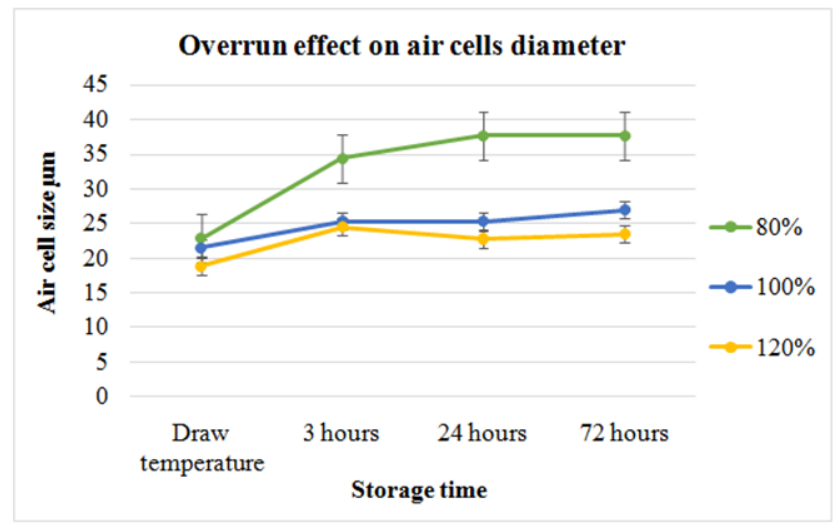

Figure I4 Difference in mean size of air cells with $80 \%, 100 \%$ and I20\% overrun in ice cream after storage of 3,24 and 72 hours at $-20^{\circ} \mathrm{C}$ on microscopic slides

\section{Whey protein effects}

Non-fat dry milk in ice cream was replaced with WPr (Whey processing) and WSr (Whey source) that were VECSD (Vacuum evaporated and spray dried after lactose crystallization) and UFVECSD (Ultrafiltered, vacuum evaporated and spray dried after lactose crystallization) to check their effects on physicochemical and sensory characteristics. Both were added at concentration of $20 \%$,
$60 \%, 80 \%$ and $90 \%$ in non-fat ice cream and non-fat yogurt. Ice cream was prepared by following standard procedure without using any fat addition. Analysis of ice cream samples were done for $\mathrm{pH}$, acidity, viscosity, penetration, meltdown, syneresis, sensory properties. Both whey proteins had no effect on $\mathrm{pH}$ and titratable acidity of yogurt at any level. There was reduction of syneresis after storage of one month observed at $60 \%, 80 \%$ and $90 \%$ level when UFVECSD used. Whey processing like ultrafilteration had the greater effects on reduction of syneresis. Whey proteins also reduced the viscosity of yogurt at all concentration levels even at small concentration might be due to denaturation of proteins during storage. Sensory evaluation resulted in higher scores of flavor for UFVECSD from jersey at $80 \%$ level. While on other hand, whey sources had no effect on $\mathrm{pH}$ of ice cream as it was decreased at higher levels of WPCs. Whey sources and whey processing both had significant effects on viscosity of ice cream based on usage percentage. UFVECSD from jersey had increased viscosity at all percentages as compared to control sample. Except J-VECSD, after storage of half month, drainage was almost similar in control and whey based ice cream samples. Drainage was enhanced resulting in less stability of emulsion in non-fat ice cream samples. Moreover, drainage was higher in samples with mixed whey protein contents. Quality of melting was reduced in samples with mixed whey protein contents while J-UFVECSD at $60 \%$ level after storage of one month showed greater resistance of melting. Melting time was reduced with enhancing whey contents. Texture and body of ice cream were improved at all usage percentages of jersey milk either VECSD or UFVECSD processed but there was no significant difference. ${ }^{20}$

General functional properties of whey based milk and milk related products were reported for their beneficial effects. It was reported that viscosity of ice cream improves as a result of higher water binding and smaller ice crystal formation due to lower ice to water transition. Moreover whey proteins retain the maximum air during incorporation of air and prevent the shrinkage or collapsing of air cells. They stabilize the air cells by forming emulsion with fat particularly phospholipids and prevent the shock due to heating. During whipping, agglutination of fat is directly influenced by the whey proteins. Products containing whey have dairy and sweet flavor that is intense whey like when whey is used at high level but whey flavor can be masked with the addition of fruity flavors, citric, lactic and malic acids (organic acids). Furthermore, stability during freeze-thaw process can be enhanced with whey addition because it maintains the freezing and transition properties. As it enhances the viscosity of ice cream so the product has better mouthfeel, creaminess, smoothness and improves the milkiness or opacity of product. Moreover, flavors and flavor chemicals get adsorbed on whey proteins and their adsorption is directly affected by increasing whey contents. Interaction occurs between whey and hydrocolloids or starch hydrolysates that results in gummy and sticky products so care must be taken when whey isolates and concentrates has to be added. ${ }^{21}$

In a study, vanilla flavored ice cream was prepared using different percentages of whey protein concentrates and milk protein concentrates to check their effect on quality. Emulsifiers and stabilizers were not added in any of the ice cream sample. The treatments contained the WPC and MPC I concentrations as given below (Table 6); Results of concerned study included the ash contents determination that was lowered because of increasing protein concentrates. Whey protein concentrates caused more reduction of ash percentage than the milk protein concentrates that were $7.16 \%$ in contrast to $2.79 \%$ due to presence of WPC. Moreover, lactose was higher in $\mathbf{T}_{2}$ and $\mathbf{T}_{5}$ because of decreased protein contents relative to other treatments 
that had lower lactose percentage resulting from enhanced proteins hence increase in acidity also occurred. Due to higher percentages of other components in $\mathbf{T}_{1}$ freezing point was found lowest but other treatments that contained WPC and MPC at same level also had the same freezing point such as $30 \%$ in both $\mathbf{T}_{2}$ and $\mathbf{T}_{5}$. Viscosity of ice cream was not affected by whey protein concentrates while it was found same or lowered in treatments containing milk protein than the treatment 1. Might be due to less freezing point, heat removal (draw temperature) of $\mathbf{T}_{1}$ was less. All samples excluding $\mathbf{T}_{3}$ had the same overrun values as data shown in Figure 14. Small sized ice crystals observed possibly due to lowered availability of free water because

Table 6 Percentages of protein concentrates in ice cream from both sources of its binding with $\mathrm{CN}$ and WP. Adsorption of proteins on the surface of ice crystals also prevented their size increase. Heat shock in $\mathbf{T}_{7}$ caused the collapsing defect in air cells might be as a result of higher contents of protein which in turn caused the destabilization. Sensory analysis turned into more acceptability of ice creams compared to $\mathbf{T}_{1}$ resulted from lowered coldness. Desirable texture was found in all samples except $\mathbf{T}_{1}$ while relatively vanilla flavor was reduced in $\mathbf{T}_{4}$ indicating the masking of flavor because of increased whey protein concentrates..$^{22}$ From the study, question could be raised that why shrinkage occurred at higher contents of MPC during heat shock and such defects might be eliminated (Figure 15).

\begin{tabular}{|c|c|c|c|c|c|c|}
\hline \multirow{2}{*}{$\begin{array}{l}\text { Treatments } \\
\text { TI }\end{array}$} & \multicolumn{2}{|c|}{ Whey protein concentrates } & \multicolumn{3}{|c|}{ Milk protein concentrates } & \multirow{2}{*}{$\begin{array}{l}\text { Protein concentration \% } \\
3.78\end{array}$} \\
\hline & - & - & - & - & - & \\
\hline $\mathrm{T} 2$ & $30 \%$ & & & & & 4.91 \\
\hline T3 & 60 & & & & & 6.05 \\
\hline $\mathrm{T} 4$ & & $90 \%$ & & & & 7.18 \\
\hline T5 & & & $30 \%$ & & & 4.9 \\
\hline T6 & & & & $60 \%$ & & 6.05 \\
\hline T7 & & & & & $90 \%$ & 7.18 \\
\hline
\end{tabular}

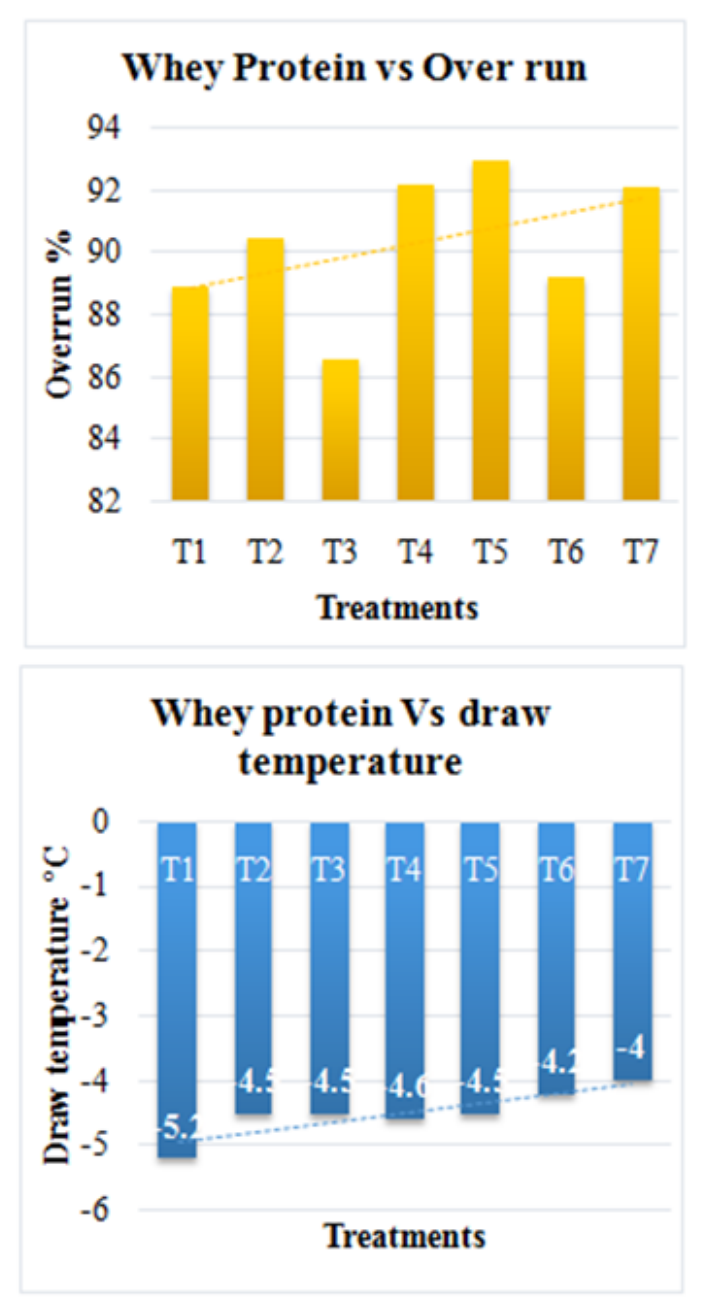

Figure 15 Physical properties of ice cream with the addition of WPC and MPC.

\section{Emulsifier effects}

Ice cream made with fat concentration at low level $(2 \%)$ and differed in percentages of emulsifiers. Added emulsifiers types were the lecithin, $40 \% \alpha$-monoglycerides, $70 \% \alpha$-monoglycerides, blend of mono and di-glycerides with polysorbate 80.12 samples were made using each emulsifier at 3 different level and named P, F, S and L on the basis of blend concentration. S emulsifier was comprised of 70:30 ratio of mono and di-glycerides, $\mathrm{F}$ comprised of 40:60 ratio of mono and di-glycerides, L comprised of lecithin only while P comprised of 80:20 percent ratio of monoglycerides and di-glycerides with polysorbate 80 . After preparation of ice cream, compositional and other characteristics were measured. Compositional analysis resulted no change in acidity and $\mathrm{pH}$ even among any treatment or amulsifiers type. On the other hand, increase in emulsifier caused enhancement in time of flow. Highest flow time was observed in $70 \% \alpha$-monoglycerides containing samples; same flow time in lecithin, blended polysorbate 80 and $40 \% \alpha$-monoglycerides containing samples while control had the lowest flow time relative to others. Viscosity also enhanced which in turn increased the body smoothness and melting resistance as a result decrease in whippibility occurred. Moreover, size of ice crystals was reduced with emulsifier possibly due to lowered surface tension due to interaction between water and emulsifier. Emulsifiers showed no interaction with protein of milk. It was assumed that ice crystals of small size were resulted from less water for freezing due to its binding with emulsifier at hydrophilic end. Furthermore, during storage frozen milk products were resisted from heat shock. Heat shock stability was highest in $70 \% \alpha$-monoglycerides, $40 \% \alpha$-monoglycerides and blended polysorbate 80 added ice cream samples. During storage of 12 weeks, there was observed neither wheying off nor shrinkage in any samples of ice cream. Sensory analysis showed that scores of flavor were not affected by emulsifiers level but flavor during storage was changed in all samples. Lowest flavor score in L type while highest in $40 \% \alpha$-monoglycerides, blended polysorbate 80 and control samples were given. Likewise, iciness and coarse fell was lowest in F type. It was concluded from the study that ice cream consistency and heat shock stability were increased with emulsifiers. ${ }^{23}$ 
In the current study, hydroxpropyl methyl cellulose, $72 \% \alpha$-MG (monoglycerides) and 52\% $\alpha-\mathrm{MG}$ were added at three different levels in ice cream preparation without fat. Treatments were the following (Table 7); After the manufacturing of ice cream following standard procedure, sensory and other characteristics of ice cream mix were determined. Acidity and $\mathrm{pH}$ were not differed significantly. Treatments including EM1, EM2 and control showed no change in flow time (70.3-75.2 seconds) but relative to control EM225 exhibited increased flow time. Comparatively, HPC added mixes took more time to flow that were higher than the water and EM added mixes. There was a direct relationship between the increase of flow time and HPC concentration. Binding of water with HPC caused viscosity enhancement which in turn raised the flow time. Whipping rate of ice cream had been considered high if it was up to 300seconds hence 229.3-264.5 seconds taking mixes were of higher rates of whipping. Moreover, overrun, frozen ice cream viscosity and machine efficiency during whipping had affected the rate of whipping. EM1, EM2 and control except HPC showed non-significant change of freezing points while it was reduced in all HPC treatments. As the stability of air cells had been due to phospholipids, emulsifiers and proteins that resulted in increased whipping rate. But compared to control, whipping and final volume were lowered in EM1 and EM2 mixes after whipping of 20minutes. ${ }^{24}$

Table 7 Composition of emulsifiers and stabilizers among treatments of nonfat ice cream

\begin{tabular}{ll}
\hline Treatment & Concentration \% \\
\hline Emulsifier I (52\% $\alpha$-monoglycerides) & \\
EMII5 & 0.15 \\
EMI20 & 0.2 \\
EMI25 & 0.25 \\
Emulsifier 2 (72\% $\alpha$-monoglycerides) & \\
EM215 & 0.15 \\
EM220 & 0.2 \\
EM225 & 0.25 \\
HPC (Hydroxypropylmethyl cellulose) & \\
HPC15 & 0.15 \\
HPC20 & 0.2 \\
HPC25 & 0.25 \\
\hline
\end{tabular}

Elevation of whipping time also showed no volume difference in treatments with EM1 and EM2 while as compared to control ability of whipping was more in HPC added mixes after 20minutes. Ability of whipping was also increased because of fat absence as fat reduces foam by dislodging protein from surface of air-mix phase. Generally, draw temperature had decreased among treatments so it resulted in product with small sized ice crystals. $-3.89^{\circ} \mathrm{C}$ of draw temperature could freeze the $33 \%$ water but in nonfat ice cream $<33 \%$ of water might have frozen and increased draw temperature resulted from effect of air insulation. Meltdown and overrun were not differed among treatments of nonfat ice cream. Mean size change of ice crystals was similar among all treatments after storage of 1-12 weeks. Size of ice crystals in EM225, EM215, EM115 and EM125 was smaller than the HPC15, HPC25 and control. During storage of 1-12 weeks, increase of $10 \mu \mathrm{m}$ occurred in size of ice crystals. With added HPC $(0.25 \%)$, size was not reduced in nonfat ice cream but $0.15 \%$ HPC caused crystals of smaller size. EM1 and EM2 at $0.15 \%$ and $0.25 \%$ increased the size in largest category during 12 weeks. On other hand, ice crystals size was restricted by emulsifier addition as they assisted in stable foam through formation of balanced air cells with smaller sized air cells. It was concluded that HPC had no improvement in stability of heat shock but whip ability improved. Moreover this ice cream was gummy as compared to other ice creams (Figure 16). ${ }^{23}$

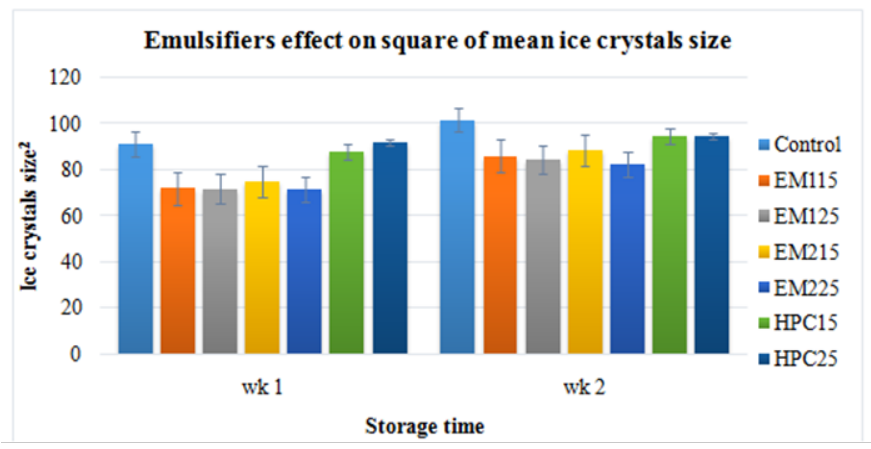

Figure 16 Effect of emulsifiers and single stabilizer on mean size of ice crystals of ice cream.

\section{Conclusion}

Because of ice cream being a complex colloidal system, there is need to consider many aspects during its manufacturing regarding its desirable taste, mouth feel, flavor, body and texture. Slight changes in any of the constituent of the ice cream may result in defects that can destroy the structure of ice cream. In parallel to good effects, damages also occur in ice cream as a result of mishandling and excess or less use of ingredients. Some defects cannot be eliminated by altering the constituents proportion like flavor rancidity, non-uniformity in color and defects in base flavor. On other hand, some of the defects can be eliminated by altering constituents proportion as they happen due to poor mix balance such as insufficient total solids, stabilizers, emulsifiers, lacking of richness and sandiness or course feel due to excess milk-solids-not-fat. Components of ice cream either have separate effects or synergistic effects when used in combination with other components. Furthermore, some components affect ice cream in various ways such as stabilizers which thickens the ice cream, improve whip ability, bind free water, reduce meltdown, help avoiding wheying off and maintain structure. But on other hand excess use may cause clumping and reduce flow rate. So, there is need of further research in field of ice cream manufacturing to establish further improvements in overall appearance along with physical characteristics to meet the changing demands of consumers and decorate the ice cream with chocolate pieces, roasted nuts and many other food items.

\section{Acknowledgements}

None.

\section{Conflict of interest}

The authors declare that there is no conflict of interest.

\section{References}

1. Arbuckle WS. Ice cream. Springer Science \& Business Media. 2013.

2. Marshall RT, Goff HD, Hartel RW. Ice cream. Springer. 2012;56-58.

3. Kilara A, Chandan RC, Hui YH. Ice cream and frozen desserts. Handbook of food products manufacturing. 2007;593-633. 
4. Sofjan RP, Hartel RW. Effects of overrun on structural and physical characteristics of ice cream. International Dairy Journal. 2004;14(3):255262 .

5. Frøst MB, Heymann H, Bredie WL, et al. Sensory measurement of dynamic flavour intensity in ice cream with different fat levels and flavourings. Food Quality and Preference. 2005;16:305-314.

6. Granger C, Leger A, Barey $\mathrm{P}$, et al. 2005. Influence of formulation on the structural networks in ice cream. International Dairy Journal. 15(3):255-262.

7. El-Rahman AA, Madkor SA, Ibrahim FS, et al. Physical characteristics of frozen desserts made with cream, anhydrous milk fat, or milk fat fractions. Journal of Dairy Science. 1997;80(9):1926-1935.

8. Koxholt MMR, Eisenmann B, Hinrichs J. Effect of the fat globule sizes on the meltdown of ice cream. Journal of Dairy Science. 2001;84(1):3137.

9. Prindiville EA, Marshall RT, Heymann H. Effect of milk fat, cocoa butter, and whey protein fat replacers on the sensory properties of lowfat and nonfat chocolate ice cream. J Dairy Sci. 2000;83(10):2216-2223.

10. Koeferli CRS, Piccinali P, Sigrist S. The influence of fat, sugar and nonfat milk solids on selected taste, flavor and texture parameters of a vanilla ice-cream. Food Quality and Preference. 1996;7(2):69-79.

11. Li Z, Marshall R, Heymann H, et al. Effect of Milk Fat Conten on Flavor Perception of Vanilla Ice Cream1. Journal of Dairy Science. 1997;80(12):3133-3141.

12. Buyck JR, Baer RJ, Choi J. Effect of storage temperature on quality of light and full-fat ice cream. Journal of Dairy Science. 2011;94(5):22132219.

13. Soukoulis C, Lebesi D, Tzia C. Enrichment of ice cream with dietary fibre: Effects on rheological properties, ice crystallisation and glass transition phenomena. Food Chemistry. 2009;115:665-671.

14. Karaman S, Toker OS, Yüksel F, et al. Physicochemical, bioactive, and sensory properties of persimmon-based ice cream: Technique for order preference by similarity to ideal solution to determine optimum concentration. Journal of Dairy Science. 2014;97(1): 97-110.
15. Kaya S, Tekin AR. The effect of salep content on the rheological characteristics of a typical ice-cream mix. Journal of Food Engineering. 2001;47:59-62.

16. Akin MB, MS Akin, Z Kirmaci. Effects of inulin and sugar levels on the viability of yogurt and probiotic bacteria and the physical and sensory characteristics in probiotic ice-cream. Food Chemistry. 2007;104(1):9399.

17. Bahramparvar M, Mazaheri Tehrani M. Application and functions of stabilizers in ice cream. Food Reviews International. 2011;27(4):389407.

18. Minhas KS, Sidhu JS, Mudahar GS, et al. Flow behavior characteristics of ice cream mix made with buffalo milk and various stabilizers. Plant Foods for Human Nutrition. 2002;57(1):25-40.

19. Soukoulis C, Chandrinos I, Tzia C. Study of the functionality of selected hydrocolloids and their blends with $\kappa$-carrageenan on storage quality of vanilla ice cream. LWT-Food Science and Technology. 2008;41:18161827.

20. Haque ZU, Ji T. Cheddar whey processing and source: II. Effect on non-fat ice cream and yoghurt. International Journal of Food Science \& Technology. 2003;38:463-473.

21. Young S. Whey products in ice cream and frozen dairy desserts. Applications Monograph. Ice cream. US Dairy Export Council. 2007;e3.10:1-12.

22. Patel MR, Baer RJ, Acharya MR. Increasing the protein content of ice cream. J Dairy Sci. 2006;89(5):1400-1406.

23. Baer RJ, Wolkow MD, Kasperson KM. Effect of Emulsifiers on the Body and Texture of Low Fat Ice Cream1. Journal of Dairy Science. 1997;80(12):3123-3132.

24. Clarke C. The science of ice cream. Royal Society of Chemistry. Unilever, Colworth Science Park, Bedford, UK. 2015;69-113. 